\title{
ОСНОВЫ ТЕОРИИ И МЕТОДИКИ РАЗВИТИЯ СВЯЗНОЙ ПИСЬМЕННОЙ РУССКОЙ РЕЧИ ОБУЧАЕМЫХ НА МАТЕРИАЛЕ ИЗЛОЖЕНИЙ ПО ВОПРОСАМ
}

\section{FUNDAMENTALS OF THE THEORY AND METHODS OF DEVELOPMENT OF CONNECTED WRITTEN RUSSIAN SPEECH BY STUDENTS ON THE MATERIAL OF STATEMENTS ON QUESTIONS}

O. Ayvazyan V. Osadchaya

Summary: The article is devoted to the consideration of the foundations of the theory and methodology for the development of coherent written Russian speech of students in the process of working on the presentation of questions. The work describes the main categories: speech, language, presentation, coherent speech. Various scientific works on the problem of the development of coherent written speech, from the most ancient period to the present, are analyzed.

The article notes a system of step-by-step methods of writing a presentation, including: an introductory conversation; mechanisms to facilitate the perception of the text; discussion of the content of the text; analysis of the content of the text; work on drawing up a plan; oral presentation of the content of the text; work on the spelling of the text; writing a presentation. The work points out that the presentation, as a technique for imitating a model, is designed to implement two fundamental functions: perception and reproduction of a speech fragment. Also in the manuscript, the fundamental techniques and perception of the text are highlighted: reading the text by a mentor; reading the text by the learner; reading and listening to the text together. The results of a statement are presented, aimed at determining the degree of formation of the written Russian speech of students on the basis of the presentation on the issues. It also indicates the main mistakes and shortcomings made by the trainees in the process of work and notes that the success of the development of coherent written Russian speech in the process of working on the presentation depends on how thorough the preliminary (pre-verbal) preparation was,

In the conclusion is made about the results of the study, and on the basis of which some practical recommendations are proposed for improving the methodology for working on the presentation.

Keywords: language, speech, presentation, coherent speech, written speech, theory and methods of speech development.

\section{Введение}

современный период становления и развития системы образования в условиях обновляющихся информационно-коммуникативных технологий од-
Айвазян Оксана Оганесовна

К.п.н., дочент, Кубанский государственный университет физической культуры, спорта и туризма, г. Краснодар

O.O.Ayvazyan@mail.ru

Осадчая Валерия Петровна

К.филол.н., дочент, Кубанский государственный университет физической культуры, спорта и туризма,

2. Краснодар

luckyvalery@mail.ru

Аннотация: Статья посвящена рассмотрению основ теории и методики развития связной письменной русской речи обучаемых в процессе работы над изложением по вопросам. В работе описываются основные категории: речь, язык, изложение, связная речь. Анализируются различные научные труды по проблеме развития связной письменной речи, начиная с древнейшего периода и по настоящее время.

В статье отмечается система поэтапной методики написания изложения, включающая: вступительную беседу; механизмы, способствующие восприятию текста; обсуждение содержания текста; анализ содержания текста; работу по составлению плана; устное изложение содержания текста; работу над орфографией текста; написание изложения. В работе указывается на то, что изложение, как прием подражания образцу призвано реализовывать две основополагающие функции: восприятие и воспроизведение речевого отрывка. Также в рукописи выделяются основополагающие приемы и восприятия текста: чтение текста наставником; чтение текста обучаемым; чтение и прослушивание текста в совокупности.

Приводятся результаты констатирующий срез, направленного на определения степени сформированности письменной русской речи обучаемых на материале изложения по вопросам. А также указываются основные ошибки и недочеты, допущенные обучаемыми в процессе работы и отмечается то, что успешность развития связной письменной русской речи в процессе работы над изложением зависит от того насколько тщательна была предварительная (предречевая) подготовка,

В заключении делается вывод о результатах исследования, и на основании чего предлагаются некоторые практические рекомендации по совершенствованию методики работы над изложением.

Ключевые слова: язык, речь, изложение, связная речь, письменная речь, теория и методика развития речи.

ной из приоритетнейших задач различных социальных институтов государства (формальных и неформальных) является формирование навыков речевой деятельности и объективной потребности у молодежи овладевать речевыми знаниями и умениями. Обоснованием 
представленному умозаключению служит то, что в условиях социальной реальности, в век развития информационно-коммуникативных технология и возрастания требований к речемыслительному процессу личности важнейшим условием социальной адаптации молодого поколения в социуме является пополнение знаний и умений, отвечающих веяниям и потребностям современности. Освоение речевых навыков - «фундамент», без которого невозможно мирное сосуществование членов современного поликультурного общества. Так, основными понятийными категориями и средством реализации речевой деятельности являются «язык» и «речь». Указанные дефиниции возникли в далеком прошлом из потребности личности осуществлять речевое взаимодействие, данная цель сохраняется и в настоящий период. «Основным фактором эффективного формирования коммуникативной компетентности является процесс обучения основам языкознания, включающим развитие знаний о языке и речи» $[1$, с. 62].

Язык - является важнейшим средством речеизъявления, что указывает на необходимость обучения языку как средству общения [3, с. 367].

Обучение свободному речеизъявлению невозможно без формирования знаний о языке и речи в совокупности, поскольку воплощением языка является речь, речевая деятельность, без которой язык мертв.

Речь - вид коммуникативной деятельности человека, исторически сложившаяся форма общения людей. Речь является самым универсальным средством общения, поскольку в передаче информации при помощи речи менее всего теряется смысл общения [2, с. 125].

Без речи невозможно осуществлять обмен информацией, а без высокого уровня языковых, коммуникативных знаний и элитарного, либо средне-литературного типа культуры речи нельзя выстроить эффективный процесс коммуникативного взаимодействия. При этом, объем информационных потоков все более возрастает, ориентируясь на увеличивающиеся требования и потребности в речи. Итак, не приходиться сомневаться в важности высокого уровня владения связной письменной русской речью. При этом одной из форм реализации связной письменной русской речи является изложение. Изложение представляет собой письменную творческую деятельность, способствующую развитию связной речи, так как позволяет сформировать навыки воспроизведения первоисточника и создания на его основе собственного текста.

На основании отмеченного, целью данной статьи является выявление уровня сформированности связной письменной русской речи обучаемых при работе над изложением и разработка методической системы, направ- ленной на ее совершенствование.

\section{Обзор ^итературы}

Теоретико-методологические основы формирования связной письменной русской речи раскрываются в научных трудах ученых различных областей наук, среди которых: М.Р. Львов, И.Д. Морозова, С.Л. Рубинштейн, К.Д. Ушинский, Л.П. Федоренко, Н.М. Шанский, М.Х. Шхапацева, и др.

Так, например, М.Р. Львов, особо отмечал значимость развитой связной речи «процесс развития речи невозможен без эмоций, без увлеченности, поэтому главное это развитие гибкости, точности и разнообразия средств выражения мысли» [5, с. 20].

С.Л. Рубинштейн отмечал, что «Связность собственно речи означает адекватность речевого оформления мысли говорящим или пишущим с точки зрения ее понятности для слушателя или читателя» [6, с. 442].

Связная речь - это форма речи, понятность которой может быть достигнута благодаря ее собственному предметному содержанию [7, с. 69].

Каждый человек должен уметь передавать содержание чужого текста связно и логично, как в устной, так и в письменной форме. В этой связи, необходимо отметить то, что одним из приемов развития связной письменной речи является изложение, требующее логически и грамматически правильно, без искажения передавать чужую речь, а также понимать своеобразие письма. Несмотря на то, что изложение - это вид письменной русской речи, реализуемые через подражание, оно позволяет выражать самостоятельные проявления, активизируя мыслительные процессы обучаемых, так необходимых для всестороннего речевого развития личности.

Профессор М.Х. Шхапацева в аспекте рассмотрения особенностей формирования связной письменной русской речи на материале изложений в своих научных трудах указывала на то, что «изложение художественных текстов мастеров слова приобщает обучаемых к лучшим образцам языка, способствует формированию правильных речевых навыков, очищает речь, повышает речевую культуру, прививает художественный вкус и развивает языковое чутье» $[9$, с. 69].

Рассмотрев труды ученых, раскрывающих основы развития связной письменной речи приходим к логическому умозаключению о том, что речевое развитие обучаемых в современном его понимании означает активное, практическое усвоение различных сторон языка и совершенствование речевой культуры в целом. 


\section{К вопросу о методике развития связной письменной речи в прочессе работы наА изложением}

Основной задачей образовательных организаций является всестороннее развитие речи обучаемых, однако же обнаруживается то, что молодежь сталкивается с такой проблематикой, как неумение, либо недостаточное умение связно и логично устно и письменно высказываться, из чего следует необходимость придания большей приоритетности данной задачи. Без овладения надлежащими навыками речевой деятельности невозможно быть на уровне с иными лицами в условиях современного рынка труда.

В рамках овладения навыков свободного речетворчества необходимо совершенствовать связную письменную речь обучаемых, что может быть реализовано посредством обучения теории и методике написания изложения.

Еще с древних времен греки отмечали особую важность такой технологии развития речевых навыков, как подражание образцу, считая ее одной из эффективнейших методик обучения в аспекте совершенствования ораторского мастерства или искусства красноречия. В связи с этим изложения важны в процессе обучения, воспитания, интеллектуального и речевого развития.

Так, древнегреческий философ Аристотель в своем труде «Риторика» изложил особенности построения речевого высказывания, основы формирования навыков связного изложения материала, виды аргументов и способы их применения в речи, и др., что так важно в аспекте развития речевых навыков.

Являясь приемом подражания образцу - изложение призвано реализовывать две основополагающие функции: восприятие и воспроизведение речевого отрывка. Достижение эффективности в реализации данных функции возможно при соблюдении поэтапной методики написания изложения.

Методика развития связной письменной речи в процессе работы над изложением включает следующие этапы:

1. Вступительная беседа. В рамках данного этапа осуществляется восприятие содержания исходного материала. В ходе вступительной беседы в целях детальной проработки содержания исходного текста необходимо отметить ключевые слова и (или) словосочетания, которые в перспективе могут вызвать затруднения при написании изложения. Также необходимым является использование приема «вопрос-ответ», предполагающий обсуждение трудных моментов в тексте (условий, авторство, жизненных ситуаций и пр.) и способов выхода из них.

2. Механизмы, способствующие восприятию текста. В целях восприятия содержания текста целесообразно использовать различные техники и приемы, среди которых выделяются: чтение текста наставником; чтение текста обучаемым; чтение и прослушивание текста в совокупности.

Данный этап подготовки к написанию изложения должен содержать установку наставника, направленную на активизацию мыслеформирования и восприятия обучаемыми текста. В рамках указанной цели необходимо конкретизировать вопросы, такие как, например, «Какова основная тема текста?», «С чем связан выбор названия заголовка?», «Как можно назвать текст?», и т.д.

3. Обсуждение содержания текста. На этапе обсуждения важным является осмысление содержания текста, всех основополагающих моментов, включающих замысел, композиционную структуру, основные факты и события, и т.п.

4. Анализ содержания текста. В процессе анализа необходимо отметить то, что текст обладает смысловым, тематическим и структурным единством. Также в ходе анализа текста применяются такие приемы, как: вслушивание в содержание текста; вдумывание; установление связи между отобранными сведениями, средствами языка и передаваемым текстом.

Указанные приемы направлены на формирование сознательного восприятия высказывания, что способствует развитию навыка создавать собственный текст на основе первоисточника, т.е. подражание образцу.

Структура анализа исходного текста включает:

- беседу по содержанию текста, с целью проверки степени освоения материала обучаемыми;

- структурный анализ текста, позволяющий определить микротемы, выявить основные части и их содержание;

- языковой анализ, цель которого недопущение речевых ошибок;

- работа над орфографией текста.

5. Работа по составлению плана. В ходе составления плана важным условием является самостоятельное выполнение данной речевой деятельности. Подобная работа позволяет более эффективно освоить навыки осмысления, запоминания и воспроизведения текста. Составление плана можно причислить к одному из наиболее продуктивных приемов развития связной русской речи, поскольку в процессе осуществления данной работы необходимо применить основополагающие требования, предъявляемые к речи: правильность, точность и выразительность. 
6. Устное изложение содержания текста. Данный прием эффективнее всего в ходе подготовки к выборочным и сжатым изложениям, что связано со значительной затратой времени на самостоятельную проработку, включающую сбор материала и составление нового текста.

7. Работа над орфографией текста. Проработка основных орфографических норм, имеющихся в тексте.

8. Написание текста. При этом, в методике работы над изложением при подготовке к написанию текста обучаемыми также важным является то, что преподавателем предлагается один текст, а по итогу выходит иной, собственный текст обучаемых, подражающий исходный. Однако же достижение указанного результата возможно при условии уменьшения работы над авторскими словами и оборотами речи в целях обращения внимания обучаемых не на слово, а на эмоциональное содержание и отношения, которые скрывают слова. Осмыслив и уяснив эмоциональную составляющую текста обучаемый «пропустит» их через себя и подберет собственные слова для изложения, что в результате гарантирует, во-первых, получение разных изложений, и, во-вторых, процесс написания такого изложения будет способствовать развитию речи. В этой связи справедливо высказывание В.Л. Кошкарова: «Буквальное воспроизведение предложенного текста достаточно бессмысленно хотя бы потому, что не даёт возможность понять: как обучаемый понял текст, как он может излагать понятое, какова степень его речевого развития на репродуктивном уровне» [4, с. 98].

\section{Методы и организашия исследования}

В целях определения степени сформированности письменной русской речи обучаемых был проведен констатирующий срез на материале изложения по вопросам. В исследовании были задействованы иностранные обучающиеся 1-х курсов Кубанского государственного университета физической культуры, спорта и туризма.

Для реализации поставленной цели были сформулированы следующие задачи:

- определить уровень освоения письменной русской речи;

- выявить основные недочеты при написании изложения;

- проанализировать ошибки и неточности, допущенные обучаемыми и разработать рекомендации для их недопущения.

В целях решения отмеченных задач было предложено написать изложение по вопросам на тему «Ваше здоpовье».

«Ваше здоровье - самое ченное, что у вас есть. Плохое здоровье, болезни служат причиной отставания в росте, слабой успеваемости, плохого настроения.

На всю жизнь вам дается только один организм. Если вы небрежно обращаетесь с любимыми предметами, их можно заменить. Но заменить свой организм вы не сможете.

Сегодня вы думаете, что будете здоровы всегда. Но вы ошибаетесь. Внимательно посмотрите на окружающих вас людей. Все ли могут похвалиться крепким здоровьем? Один из главных показателей здоровья - продолжительность жизни. Там, где нет здоровья, не может быть и долголетия. Запомните - необходимо заботиться о себе и своем здоровье уже сейчас!».

Послетекстовые задания:

1. Прочитайте текст.

2. Составьте план к тексту.

3. Ответить на вопросы по тексту изложения

1) Что такое здоровье?

2) Какова причина плохого здоровья?

3) Каков главный показатель хорошего здоровья?

Слова для справок: здоровье, организм, продолжительность жизни, долголетия.

Результаты исследования показаны в нижеследующих рис. 1 и табл. 1 (в целях удобной интерпретации указаны средние показатели).

\section{Результаты и их обсужление}

Анализ результатов, проведенного исследования позволил констатировать то, что обучаемые в недостаточной мере владеют связной письменной русской речью, допускают большое количество пунктуационных и лексических недочетов, а это указывает о сконцентрированности их внимания на содержательной стороне изложения, а не на правильности письменной речи. Также допущенные логические и синтаксические ошибки, несмотря на их меньшее количество показывают то, что на подготовительном этапе обучающиеся недостаточно усвоили содержание текста, т.е. требуется более тщательная подготовка к написанию изложения.

В ходе подробного анализа изложений обучающихся были выявлены следующие ошибки и недочеты:

- нарушение точности и логичности изложения материала, характеризующиеся обрыванием мыслей или насыщением лексикой, что является свидетельством недостаточно развитой связной письменной речи, в результате чего процесс свободной речемыслительной деятельности затруднителен;

- неточное выделение абзацев, неверное построение высказываний, нарушение последователь- 


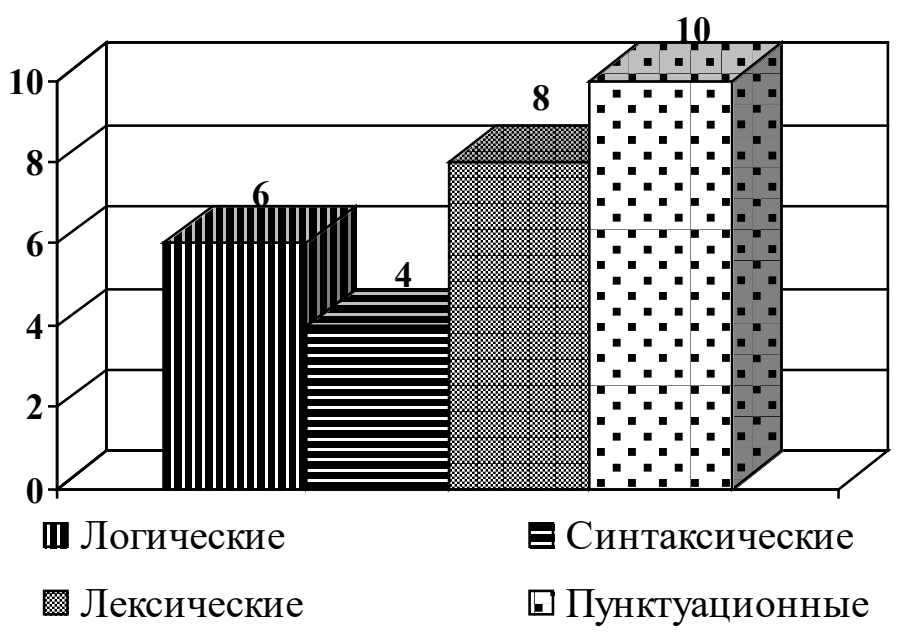

Рис. 1. Результаты исследования по виду и количеству ошибок

Результаты констатирующего среза

\begin{tabular}{|l|c|c|c|c|c|}
\hline Вид изложения & Количество обучаемых & Справились & Не справились & Количество слов в тексте & Количество предложений \\
\hline По вопросам & 20 & 14 & 6 & 93 & 12 \\
\hline
\end{tabular}

ности изложения материала указывает, как на неумение выделять микротемы текста, так и слабый уровень речевых навыков;

- имеющиеся грамматические, орфографические и пунктуационные недочеты обуславливают низкий уровень подготовленности в соответствующих разделах русского языка.

Вышеотмеченные ошибки и недочеты сковывают свободное речетворчество обучающихся, ограничивают степень их успеха в других дисциплинах и затрудняют процесс связного и логичного коммуникативно-речевого взаимодействия. В целях предотвращения подобных негативных последствий необходимо формировать навыки связной письменной русской речи обучаемых, включающие способность усваивать и верно передавать основную мысль содержания текста; умение письменно излагать материал с соблюдением всех норм и правил русской речи. Также, материал подбираемый преподавателем должен быть уместным, целесообразным и соответствовать уровню образования.

\section{Зак^ючение}

Итак, на основании всего вышеуказанного можно констатировать то, что успешность развития связной письменной русской речи в процессе работы над изложением зависит от того насколько тщательна была предварительная (предречевая) подготовка. При этом важно помнить то, что изложение является средством, формирующим и совершенствующим умения, необходи- мые при решении коммуникативных задач в различных сферах деятельности. Также необходимо отметить то, что поскольку в основе изложения как одного из приемов развития связной письменной русской речи лежит подражание образцу, обучающиеся имеют возможность составлять заранее обдуманные тексты и высказывания. Изложение является показателем степени сформированности умений обучающихся продуманно выстраивать связные высказывания, соответствующие коммуникативной цели и теме.

В соответствии с мнением М.С. Соловейчик «текст, который мы предлагаем обучаемым для изложения, - это своеобразная «помощь взрослого» в сложном деле обучения построению высказываний, помощь в накоплении речевого опыта» [8, с. 26].

При этом для того, чтобы изложение способствовало накоплению собственного речевого опыта у обучаемых необходимо соблюдение следующих условий:

1. Текст для изложения по своему содержанию должен быть: доступным для обучающихся; содержательней, богаче и выразительней речи обучающихся; композиционно несложным и иметь небольшое количество действующих лиц.

2. Изложение должно выполняться осознанно после анализа текста, включающего: тщательный подбор текста, соответствующего уровню знаний обучающихся; отбор текста, отвечающего основополагающим требованиям к речи (правильность, точность, богатство и выразительность). 


\section{ЛИТЕРАТУРА}

1. Айвазян 0.0. Коммуникативность как один из основных принципов в теории и методике развития русской речи // Современная наука: Актуальные проблемы теории и практики. Серия «Гуманитарные науки». - 2019. - № 11-2 (25 ноября 2019 г.). - С. 58-62.

2. Айвазян 0.0. Коммуникация и речь // Вестник Адыгейского государственного университета. Сер. Педагогика и психология. - 2012. - Вып. 3 (103). C. 125-129.

3. Ахманова 0.С. Словарь лингвистических терминов. - М.: Сов. энциклопедия, 1969. - 607 с.

4. Кошкаров В.Л. Обучение коммуникативно-речевым стратегиям в школе. - Петрозаводск: ГОУВПО «КГПУ», 2005. - 156 с.

5. Львов М.Р. Основы теории речи: учеб. пособие. - М.: Академия, 2000. - 248 с.

6. Рубинштейн С.Л. Основы общей психологии. - СПб: Питер, 2000. - 712 с.

7. Рубинштейн С.Л. Речь и общение. Функции речи. Развитие речи у детей // Основы общей психологии. - Т. 1 - М., 1989. - С. 442-460. 156

8. Соловейчик М.С. Как повысить эффективность изложений? // Начальная школа. - 1993. - №1. - С. 26-30.

9. Шхапацева М.Х. Развитие связной русской речи учащихся: учебное. - Майкоп, 1995. - С. 69.

๑ Айвазян Оксана Оганесовна (O.O.Ayvazyan@mail.ru), Осадчая Валерия Петровна (luckyvalery@mail.ru).

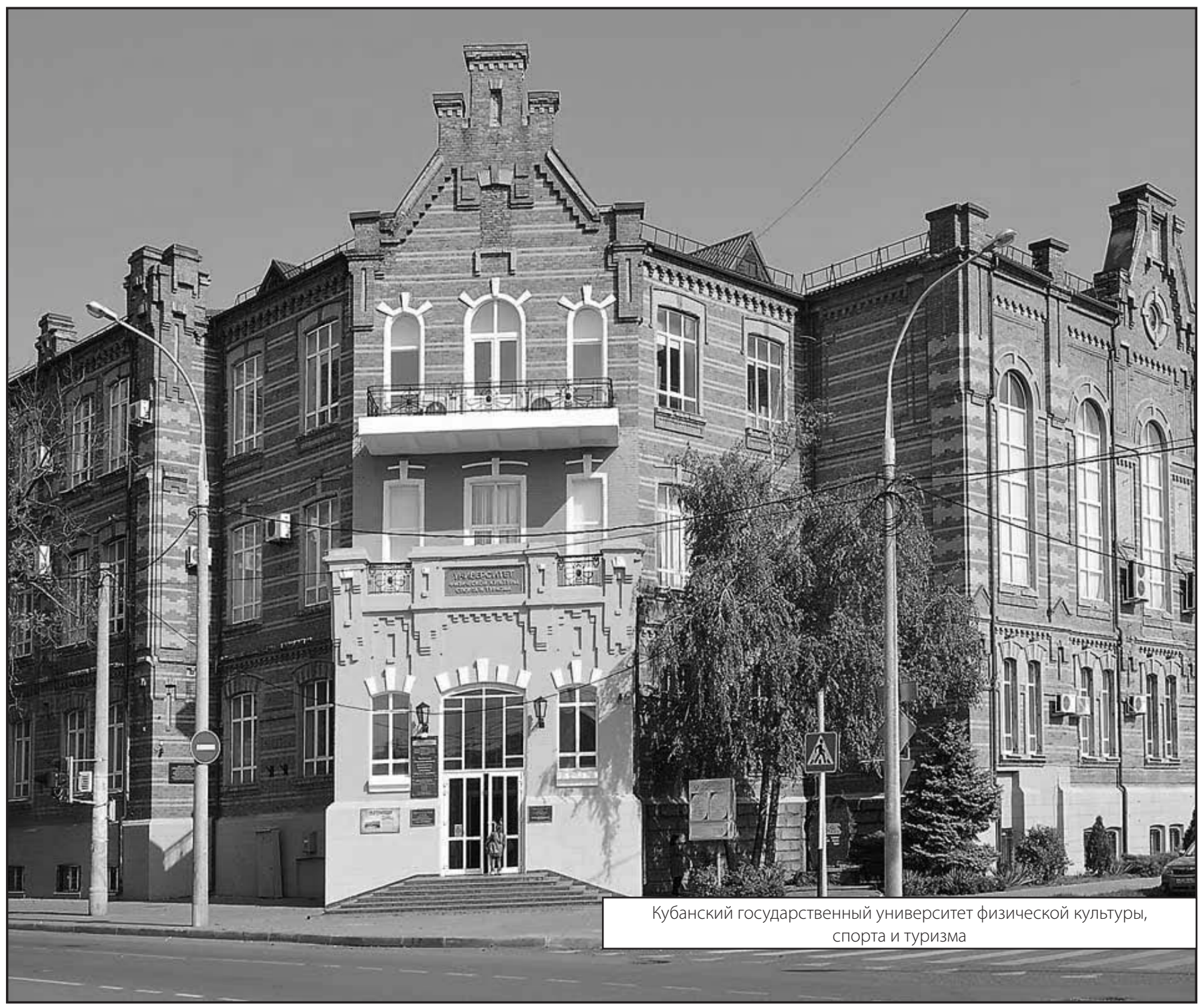

